\title{
ICU Resource Allocation in the New Millennium: Will We Say "No"?
}

\author{
David W. Crippen. Springer, New York, 2013, 351 pages. Price: \$44.82 (amazon.ca). \\ ISBN 978-1-4614-3865-6
}

\author{
Donald Griesdale, MD
}

Received: 23 March 2013/Accepted: 28 March 2013/Published online: 12 April 2013

(C) Canadian Anesthesiologists' Society 2013

This book is the third in a thought-provoking series edited by Dr. Crippen, Professor of Critical Care Medicine at the University of Pittsburg. ${ }^{1}$ The first book in the series dealt with international perspectives on the treatment of critically ill patients at the end of life. ${ }^{2}$ The second book discussed communication with patients and families at the end of life from various cultural viewpoints. ${ }^{3}$ For this current offering, Dr. Crippen has brought together authorities in the fields of critical care medicine, law, nursing, and bioethics from around the world to address some fundamental questions: How do we continue to deliver critical care in the setting of limited resources? Can or should we prioritize access to care? The assumptions are all well known to critical care physicians. Health care is a costly resource that represents an ever increasing expenditure; however, health care funding has slowed over the past few years in response to the global financial crisis. This is balanced against ever increasing expectations from patients and families for access to novel and expensive technologies and treatments. This is particularly true for intensive care where we are faced with an aging population and are willing to treat conditions previously deemed fatal.

The book is organized into four parts. In Part I, the health care systems of 12 countries (Australia, Brazil, Canada, Germany, Israel, India, Italy, The Netherlands, New Zealand, South Africa, United Kingdom, and the United States) are examined. Separate chapters allocated for each country address two fundamental questions: "Where have we been?" and "Where are we going"? To address the first question, the history of each country's

D. Griesdale, MD $(\bowtie)$

Vancouver General Hospital, University of British Columbia,

Vancouver, BC, Canada

e-mail: donald.griesdale@vch.ca current health care system, specifically the funding, delivery, and staffing of intensive care, is discussed. Each author also addresses the current landscape of rationing care within their system. The chapters on the future of health care within each country examine the anticipated demands and challenges within the context of the current system and the legal and ethical issues regarding limitation of support. Part I is summarized by Drs. Buchman and Chalfin who deconstruct the previous chapters into the salient issues facing critical care from a global perspective. For example, they contrast two systems of universal health care funded by taxation, Israel and New Zealand. Israeli citizens regard health care as a fundamental right irrespective of resource availability. The authors argue that the degree of care delivered may not be congruous with the likelihood of a meaningful outcome. In contrast, New Zealand allows physicians to manage critical care services, including prioritization decisions regarding who should be supported and for how long. Patients who are unlikely to benefit may be either denied access to critical care or offered a short trial with ongoing care contingent upon measurable improvement. As such, New Zealand is able to manage with fewer beds per capita than Israel. This discussion highlights the contrasting expectations that are founded in the social fabric of each society.

In Part II, Dr. Crippen proposes a fictional healthcare plan, "The Fair and Equitable Health Care Act (FEHCA)", to address the limitations of the current health care system in the United States, including physician compensation, payment for quality care benchmarked to outcomes, spectrum of services (primary, specialist, surgical, emergency, and critical care), nursing facilities, and compensation for medical errors and malpractice. Although this is an interesting proposal with some merits, the real benefit to FEHCA is within the subsequent three critiques that go 
well beyond the specifics outlined by the plan. For example, Dr. Whetstine delivers an interesting and comprehensive rebuttal on no-fault insurance as a whole, not simply as it relates to the FEHCA. Part III focuses on the legal and nursing viewpoints on the underlying issues outlined in the first part of the book. The legal chapter provides an excellent discussion concerning the conflicts that may arise when physician judgement clashes with family expectations and demands. This chapter will be of great interest to all practicing critical care physicians. The final part of the book looks towards the future of intensive care both in the United States and beyond.

Who should read this book? Obviously, it would appeal to individuals with an interest in the different systems of health care delivery, particularly from a global perspective. This book would also serve as an excellent foundation for anyone researching various care models throughout the globe. Nevertheless, the issues addressed in Dr. Crippen's book are fundamental to the practice of acute care medicine and especially critical care. As such, intensive care physicians who wrestle daily with questions on how to deliver care in a system with limited resources and ever expanding patient expectations will take great interest in this book.

Competing interests None declared.

\section{References}

1. Crippen $D W$. ICU Resource Allocation in the New Millennium: Will We Say "No"? Boston: Springer; 2013.

2. Crippen D, Kilcullen $J K$, Kelly $D F$. Three Patients: International Perspectives on Intensive Care at the End of Life. Boston: Kluwer Academic Publisher; 2002.

3. Crippen DW. End-of-Life Communication in the ICU: A Global Perspective. NY: Springer; 2008. 